\title{
BORAKS SEBAGAI PENGAWET BAKSO DI KECAMATAN MAMAJANG KOTA MAKASSAR
}

\author{
Muawanah $^{1)}$ \\ ${ }^{1)}$ Akademi Analis Kesehatan Muhammadiyah Makassar \\ Alamat Korespondensi: muawanah.usman@yahoo.com
}

\begin{abstract}
Abstrak
Boraks adalah jenis bahan kimia yang sering digunakan sebagai pengawet makanan yang dilarang penggunaanya oleh pemerintah karena dampaknya akan sangat merugikan kesehatan. Boraks digunakan untuk mengawetkan suatu makanan dalam waktu yang cukup lama, seperti bakso. Boraks digunakan agar bakso lebih kenyal, lebih awet dan tahan lama meskipun disimpan beberapa hari pada suhu ruang. Tujuan penelitian adalah untuk mengidentifikasi boraks pada bakso yang diperjualbelikan di Kecamatan Mamajang Kota Makassar. Metode yang digunakan dalam penelitian ini adalah metode kualitatif menggunakan metode uji nyala api. Sampel yang digunakan sebanyak 5 sampel yang diambil secara accidental sampling di beberapa pedagang bakso keliling. Hasil penelitian ini menunjukkan bahwa kelima sampel yaitu sampel A, B, C, D, dan E diperoleh hasil negatif(-). Hal ini membuktikan bahwa kelima sampel bakso yang beredar di Kecamatan Mamajang Kota Makassar tidak menggunakan boraks sebagai pengawet.
\end{abstract}

Kata Kunci: Bakso, Boraks, Uji Nyala Api

\section{PENDAHULUAN}

Beberapa zat kimia ditambahkan pada makanan yang disebut bahan tambahan pangan yang bertujuan untuk meningkatkan keawetannya sehingga makanan dapat diproduksi secara massal, atau untuk meningkatkan daya tarik bagi konsumennya dalam segi warna, rasa, dan bentuk (Lu, 2010).

Masyarakat dan industri seharusnya perlu memperhatikan bahan tambahan pangan dalam hubungannya dengan kemungkinan pemalsuan terhadap komponen yang berkualitas rendah dan kemungkinan bahaya yang ditimbulkan oleh komponen beracun dalam pangan (Cahyadi, 2009).

Pada banyak negara, terutama negara-negara maju mempunyai hukum atau peraturan tentang bahan tambahan pangan. Adapun bahan tambahan kimia yang dilarang penggunaannya menurut Peraturan Menteri Kesehatan RI adalah asam borat atau boraks, asam salisilat, dethylpyrocarbonasi, dulcin, potassium chlorate, chloramphenicol, minyak sayur terbominasi, nitrifurazon, dan formaldehid. Namun demikian, untuk bahan tambahan kimia yang dilarang tidak disertai dengan batas maksimum penggunaan karena secara umum digolongkan ke dalam senyawa yang berbahaya bagi kesehatan tubuh (Cahyadi, 2009).

Larangan penggunaan boraks juga diperkuat dengan adanya Permenkes RI No. 235/Menkes/VI/1984 tentang bahan tambahan makanan, bahwa Natrium Tetraborat yang lebih dikenal dengan nama boraks digolongkan dalam bahan tambahan yang dilarang dalam makanan, tetapi pada kenyataannya masih banyak bentuk penyalahgunaan dari zat tersebut (Tubagus, 2013).

Boraks adalah senyawa berbentuk kristal putih, tidak berbau, dan stabil pada suhu ruangan. Boraks merupakan senyawa kimia dengan nama Natrium Tetraborat $\left(\mathrm{NaB}_{4} \mathrm{O}_{7} .10 \quad \mathrm{H}_{2} \mathrm{O}\right)$. Jika larut dalam air akan menjadi hidroksida dan asam borat $\left(\mathrm{H}_{3} \mathrm{BO}_{3}\right)$. Boraks merupakan antiseptik dan pembunuh kuman, serta banyak digunakan sebagai bahan antijamur, pengawet kayu, dan antiseptik pada kosmetik. Meskipun bukan pengawet makanan, boraks sering digunakan sebagai pengawet makanan. Selain sebagai pengawet, bahan ini 
berfungsi pula untuk mengenyalkan makanan. Makanan yang sering ditambahkan boraks adalah bakso, lontong, mie, kerupuk, dan berbagai makanan tradisional seperti lemper dan alen-alen (Yuliarti, 2007).

Bakso hadir dalam beragam jenis makanan dan sangat digemari oleh masyarakat. Bakso merupakan produk dari daging, baik daging sapi, ayam, ikan, maupun udang. Bakso juga biasa digunakan dalam campuran beragam masakan lainnya, seperti nasi goring, mie goring, capcay, dan aneka sop (Widyaningsih, 2006). Meskipun bakso merupakan makanan yang memasyarakat, tetapi pengetahuan masyarakat tentang bakso yang aman dan baik dikonsumsi masih kurang. Hal ini terbukti dengan adanya bakso yang mengandung boraks dan formalin masih banyak beredar dan tetap dikonsumsi, padahal itu dapat merugikan kesehatan (Cahyadi, 2009).

Gejala keracunan boraks akut meliputi rasa mual, muntah-muntah, diare, kejang perut, bercak-bercak pada kulit, kerusakan pada ginjal, gelisah, lemah, kematian terjadi akibat kolaps pernafasan. Sedangkan pada keracunan kronik dapat menyebabkan demam, anoreksia, anuria, kerusakan ginjal, depresi, dan bingung (Rusli, 2009).

Ciri-ciri bakso yang mengandung boraks seperti lebih kenyal, lebih awet, dan tahan lama meski disimpan beberapa hari paada suhu ruang, memiliki warna pucat baik dari luar maupun bagian dalamnya dan apabila digigit maka bakso akan kembali ke tekstur semula serta apabila bakso jatuh ke lantai maka akan memantul tinggi seperti bola bekel (Joglo, 2013).

Silalahi et al., (2012) melaporkan di Kota Medan adanya kandungan boraks pada jajanan bakso, bahwa $80 \%$ dari sampel yang diperiksa ternyata mengandung boraks. Kadar boraks yang ditemukan berkisar antara 0,08- 0,29\% dari berbagai lokasi yang diteliti. Nurkholidah et al., (2012), menemukan hasil positif mengandung boraks dari sampel bakso yang dijajankan di
Pekanbaru dengan kadar boraks berkisar antara 0,48-2,32 mg/g. Sedangkan pada penelitian yang dilakukan dengan sampel bakso yang beredar di SDN Kompleks Mangkura Makassar diperoleh hasil negatif atau tidak mengandung boraks (Sultan et al., 2013).

Berdasarkan uraian diatas maka peneliti tertarik untuk melakukan penelitian tentang boraks sebagai pengawet pada bakso yang beredar di Kecamatan Mamajang Kota Makassar.

\section{METODE PENELITIAN}

\section{Alat dan Bahan}

Alat yang digunakan dalam penelitian ini adalah batang pengaduk, cawan porselen, kurs porselin, pipet tetes, tanur listrik, timbangan digital.

Bahan-bahan yang digunakan dalam penelitian ini adalah aquabides (aquades steril), bakso, $\mathrm{H}_{2} \mathrm{SO}_{4}(\mathrm{p})$, metanol, dan label, sampel bakso.

\section{Prosedur Penelitian}

Metode analisis kualitatif dengan uji nyala

Sampel bakso dihaluskan dengan lumpang, kemudian ditimbang sebanyak $10 \mathrm{~g}$. Sampel bakso yang sudah ditimbang dimasukkan ke dalam cawan porselen, dan kemudian dimasukkan ke dalam tanur dan dipijarkan pada suhu $800{ }^{\circ} \mathrm{C}$ selama 3 jam. Setelah itu sisa pemijaran ditambahkan 12 tetes $\mathrm{H}_{2} \mathrm{SO}_{4}(\mathrm{p})$ dan 5-6 tetes metanol, kemudian dibakar. Apabila timbul nyala warna hijau, maka menandakan adanya boraks.

\section{HASIL DAN PEMBAHASAN}

Penelitian ini merupakan penelitian yang bersifat observasi laboratorium dengan subjek penelitian adalah bakso yang kemungkinan mengandung boraks. Pemeriksaan analisis kualitatif kandungan boraks menggunakan metode uji nyala yang bertujuan untuk mengetahui ada tidaknya boraks pada bakso yang beredar di Kecamatan Mamajang Kota Makassar dengan jumlah sampel sebanyak 5 (lima) sampel. Adapun hasil analisis kualitatif kandungan boraks pada sampel bakso dapat dilihat pada tabel 1 . 


\begin{tabular}{ccc} 
Tabel 1. & Hasil & Identifikasi \\
\hline $\begin{array}{c}\text { Kode } \\
\text { Sampel }\end{array}$ & Pengamatan & Hasil \\
\hline A & $\begin{array}{c}\text { Nyala warna } \\
\text { orange }\end{array}$ & Negatif (-) \\
B & $\begin{array}{c}\text { Nyala warna } \\
\text { orange }\end{array}$ & Negatif (-) \\
C & $\begin{array}{c}\text { Nyala warna } \\
\text { orange }\end{array}$ & Negatif (-) \\
D & $\begin{array}{c}\text { Nyala warna } \\
\text { orange }\end{array}$ & Negatif (-) \\
E & $\begin{array}{c}\text { Nyala warna } \\
\text { orange }\end{array}$ & Negatif (-) \\
\hline
\end{tabular}

Sampel penelitian ini berupa bakso yang diperjualbelikan di Kecamatan Mamajang Kota Makassar, Sulawesi Selatan. Selanjutnya dilakukan analisis kuantitatif di Balai Besar Laboratorium Kesehatan (BBLK) Makassar, Sulawesi Selatan.

Penelitian dilakukan karena boraks sering disalahgunakan sebagai bahan tambahan pangan, boraks tidak diizinkan penggunaannya dalam makanan yang disesuaikan dengan Permenkes RI No. 1168/Menkes/Per/X/1999 tentang bahan pangan.

Berdasarkan hasil penelitian dari kelima sampel bakso yang telah diuji di laboratorium dengan metode uji nyala dimana sampel bakso yang digunakan ditimbang sebanyak $10 \mathrm{~g}$ lalu dihaluskan, kemudian sampel dimasukkan ke dalam cawan porselen untuk selanjutnya dipijarkan ke dalam tanur pada suhu 800 ${ }^{0} \mathrm{C}$ selama 3 jam. Sisa pemijaran direaksikan dengan pereaksi asam sulfat pekat 1-2 tetes dan metanol 5-6 tetes. Untuk semua sampel bakso yang diuji menghasilkan warna nyala yang menunjukkan bahwa semua sampel tersebut tidak mengandung bahan pengawet berbahaya boraks. Analisis kualitatif boraks dengan metode nyala api akan menghasilkan nyala api yang berwarna hijau dan menunjukkan bahwa sampel tersebut mengandung boraks.

Efek boraks pada makanan dapat memperbaiki struktur dan tekstur makanan. Bila boraks diberikan pada bakso/lontong akan membuat bakso/lontong tersebut sangat kenyal dan tahan lama. Tetapi makanan yang telah diberi boraks dengan yang tidak atau masih alami, sulit untuk dibedakan jika hanya dengan panca indera, namun harus dilakukan uji khusus boraks di laboratorium.

Apabila seseorang sering mengkonsumsi makanan yang mengandung boraks tidak akan langsung mengalami dampak buruk bagi kesehatan, tetapi senyawa tersebut diserap dalam tubuh secara kumulatif. Selain melalui saluran pencernaan, boraks dapat diserap melalui kulit. Dalam jumlah yang banyak, boraks menyebabkan demam, anuria (tidak terbentuknya urin), koma, merangsang sistem saraf pusat, menimbulkan depresi, apatis, sianosis, tekanan darah turun, kerusakan ginjal, pingsan bahkan kematian. Pada anak kecil dan bayi, bila dosis dalam tubuhnya sebanyak $5 \mathrm{~g}$ atau lebih dapat menyebabkan kematian, sedangkan untuk orang dewasa kematian terjadi pada dosis 10 sampai $20 \mathrm{~g}$ (Endrinaldi, 2006).

\section{KESIMPULAN}

Dari hasil penelitian identifikasi boraks dalam sampel bakso dengan reaksi uji nyala diketahui bahwa semua sampel bakso yang diuji tidak mengandung bahan pengawet berbahaya, yaitu boraks. Oleh karena itu, tidak dilakukan penelitian secara kuantitatif untuk mengetahui kadar boraks dari jajanan bakso di Kecamatan Mamajang Kota Makassar.

\section{SARAN}

Disarankan kepada peneliti selanjutnya untuk menggunakan lebih dari satu metode dalam mengidentifikasi kandungan boraks secara kualitatif agar hasilnya lebih akurat.

\section{DAFTAR PUSTAKA}

Anggrahini S, 2008. Keamanan Pangan Kaitannya dengan Penggunaan Bahan Tambahan dan Kontaminan. Jogjakarta: Universitas Gajah Mada.

Cahyadi . 2009. Bahan Tambahan Pangan. Jakarta: Penerbit Bumi Aksara.

Endrinaldi. 2006. Identifikasi dan Penetapan Kadar Boraks pada Mie Basah yang Beredar di 
Beberapa Pasar di Kota

Padang (Skripsi). Padang:

Universitas Andalas.

Lu, F.C. 2010. Toksikologi Dasar. Jakarta: Penerbit Universitas Indonesia Press.

Nurkholidah. 2012. Analisis Kandungan Boraks pada Jajanan Bakso Tusuk di Sekolah Dasar Di Kecamatan Bangkinang Kabupaten Kampar. Jakarta: Jurnal Ilmu Lingkungan.

Rusli, R. 2009. Penetapan Kadar Boraks pada Mie Basah yang beredar di Pasar Ciputat dengan Metode Spektrofotometri UV-Vis Menggunakan pereaksi kurkumin. Jakarta: Universitas Islam Negeri Jakarta.

Semar, J. 2013. Bahaya Boraks dan Formalin dalam Bakso. Available from:

http://hcioglosemar.wordpress.com/2 013/10/07/bahaya-borakdanformalin-dalambakso.

Silalahi, et al., 2012. Pemeriksaan Boraks di dalam Bakso di Medan (Skripsi). Medan: Universitas Sumatera Utara.

Sultan, P. 2013. Analisis Kandungan Zat Pengawet Boraks Pada Jajanan Bakso Di SDN Kompleks Mangkura Kota Makassar (Tesis). Makassar: Universitas Hasanuddin.

Tubagus I., Citraningtyas, G., Fatimawali. 2013. Identifikasi dan Penetapan Kadar Boraks dalam Bakso Jajanan di Kota Manado. Manado: Jurnal Ilmiah FarmasiUNSRAT. Vol. 2 No. 04.

Yuliarti Nurheti. 2007. Awas! Bahaya dibalik Lezatnya Makanan. Yogyakarta: Penerbit Andi.

Widyaningsih, D.T., Murtini, E.S. 2006. Alternatif Pengganti Formalin pada Produk Pangan. Surabaya: Trubus Agriarana. 